2. Williams DB, Pluth JR, Orszulak TA. Extrinsic obstruction of the Bjork-Shiley valve in the mitral position. Ann Thorac Surg. 1981;32: 58-62.

3. Trites PN, Kiser JC, Johnson C, Tycast FJ, Gobel FL. Occlusion of Medtronic Hall mitral valve prosthesis by ruptured papillary muscle and chordae tendineae. J Thorac Cardiovasc Surg. 1984;88:301-2.
4. Mok CK, Cheung DL, Chiu CS, Aung-Khin M. An unusual lethal complication of preservation of chordae tendineae in mitral valve replacement. J Thorac Cardiovasc Surg. 1988;95:534-6.

5. Lemke P, Roth M, Kraus B, Hohe S, Klovekorn WP, Bauer EP. Ruptured papillary muscle after mitral valve replacement with preservation of chordae tendineae. Ann Thorac Surg. 2001;72:1384-6.

\title{
Chondromyxoid fibroma of the sternum
}

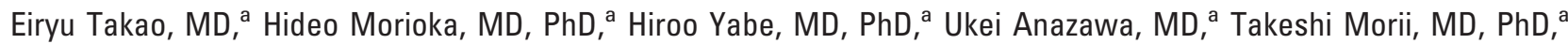

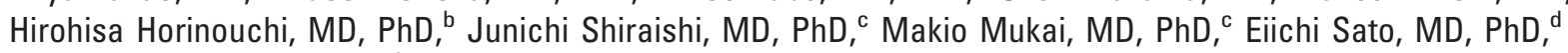
Yoshiki Hamada, MD, PhD, and Yoshiaki Toyama, MD, PhD, ${ }^{\text {a }}$ Tokyo and Yamanashi, Japan

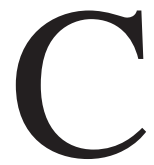

hondromyxoid fibroma (CMF) was described by Jaffe and Lichtenstein ${ }^{1}$ in 1948 and is thought to be a rare benign bone tumor, representing less than $1 \%$ of the total number of primary bone tumors. ${ }^{2}$ It predominantly affects the long bones and rarely occurs in the sternum. In this communication we report a case of CMF of the sternum with a brief review of the literature.

\section{Clinical Summary}

The patient was a 17-year-old man whose chief complaint was pain in the anterior part of the chest. He had occasionally experienced anterior chest pain since about August 2000 and had consulted a local physician because the pain was aggravated by a fall in June 2002. A plain x-ray examination had revealed a bone tumor in the sternum. The patient was first referred to us in July 2002, and he was admitted for surgery in September 2002. During the initial physical examination, a tender swelling that was mildly warm to palpation was found in the middle of the lower sternum. A plain x-ray film showed an eccentrically located multilobular radiolucency with mild calcification in the lower sternum. Computed tomography revealed an osteolytic lesion with discrete calcification in the bone marrow of the sternum (Figure 1, A). The lesion was visualized as an isointense area by T1-weighted mag-

From the Departments of Orthopaedic Surgery and Thoracic Surgery, ${ }^{\mathrm{b}}$ School of Medicine, Keio University, Tokyo, Japan; the Department of Diagnostic Pathology, Keio University Hospital, Tokyo, Japan'; and the Department of Orthopaedic Surgery, University of Yamanashi, Faculty of Medicine, Yamanashi, Japan. ${ }^{\mathrm{d}}$

Received for publication March 15, 2006; accepted for publication April 20, 2006.

Address for reprints: Hideo Morioka, MD, PhD, Department of Orthopaedic Surgery, School of Medicine, Keio University, 35 Shinanomachi, Shinjuku-ku, Tokyo 160-8582, Japan (E-mail: morioka@sc.itc.keio.ac.jp).

J Thorac Cardiovasc Surg 2006;132:430-1

$0022-5223 / \$ 32.00$

Copyright $\odot 2006$ by The American Association for Thoracic Surgery doi:10.1016/j.jtcvs.2006.04.023 netic resonance imaging and as a well-marginated high-intensity area by $\mathrm{T} 2$-weighted magnetic resonance imaging with a slightly lobular pattern (Figure 1, B). On the gadolinium-enhanced T1weighted image the tumor was well enhanced. On the basis of these findings, a malignant cartilaginous tumor of the sternum was suspected, and a biopsy of the lesion was obtained.

Histologic examination of the biopsy specimen revealed a slightly lobular architecture composed of myxoid matrix populated by stellate or elongate cells with eosinophilic cytoplasmic processes. These myxoid areas were interspersed in a background of more cellular regions containing dilated sinusoidal vessels and focal hemorrhage. These findings were compatible with $\mathrm{CMF}$ because there were practically no mitotic figures and the cellular atypia was minimal (Figure 2, $A$ and $B$ ). On the basis of these histologic findings, the following surgical procedure was performed. A part of the cortex was removed from the anterior surface of the sternum. The lesion in the bone marrow was completely curetted, and the remaining lesion was ground off with an air drill. The space after curettage was completely filled with bone allograft fragments. The histologic diagnosis of the surgical specimen was CMF as suspected from the biopsy. The patient's clinical course has been uneventful with no local recurrence thus far, 3 years 6 months postoperatively.

\section{Discussion}

CMF is the least common benign cartilaginous tumor, and only 106 cases were registered in the Japanese Bone Tumor Registry in the 21 years from 1972 to $1993 .^{3}$ It accounts for $0.45 \%$ of all primary bone tumors. The most prevalent site is the metaphysis of long bone, and the affected sites reported have been the tibia in 33 cases $(31 \%)$, the femur in 23 cases $(22 \%)$, and the humerus in 9 cases $(8.5 \%)$. During the above period, 71 cases of sternal primary bone tumors were reported, including 18 cases of osteochondroma, 15 cases of chondrosarcoma, and 14 cases of chondroma. Among these tumors, particular caution is required to differentiate chondrosarcoma from CMF. Because of the presence of pleomorphic cells with hyperchromatic nuclei, the histologic diagnosis of CML may sometimes be difficult and an erroneous diagnosis of chondrosarcoma may result.

To the best of our knowledge, there have been no reports of $\mathrm{CMF}$ 

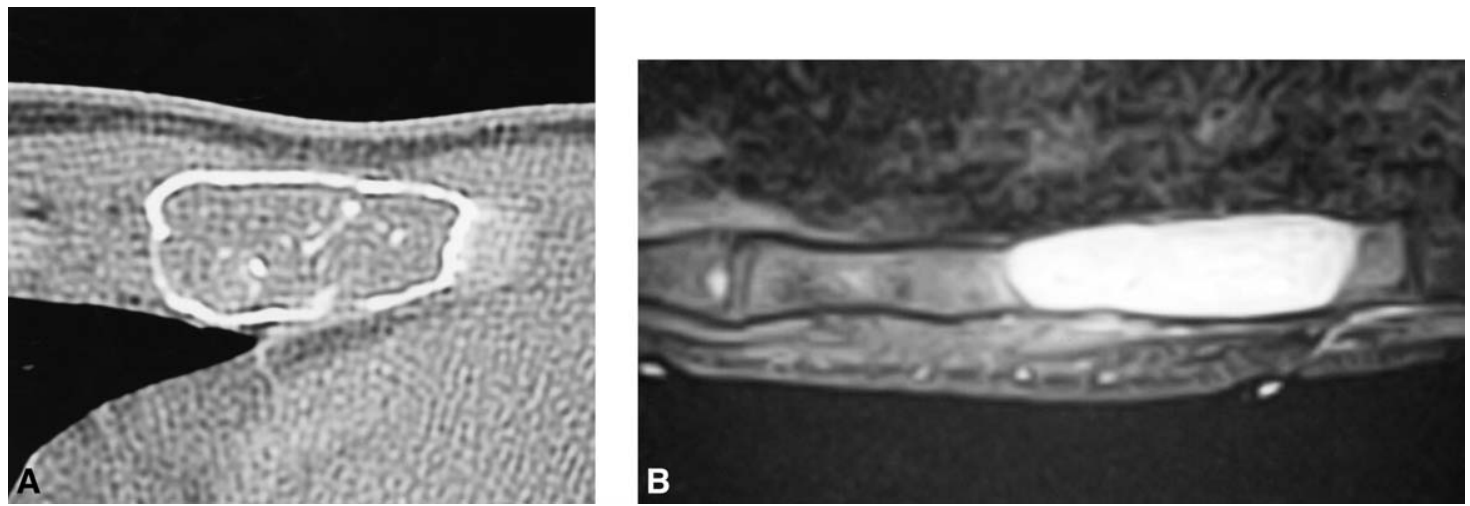

Figure 1. A, Computed tomography revealed an osteolytic lesion with discrete calcification in the bone marrow of the sternum. B, On magnetic resonance imaging, the tumor was visualized as a well-marginated high-intensity area with a slightly lobular pattern in the T2-weighted image.
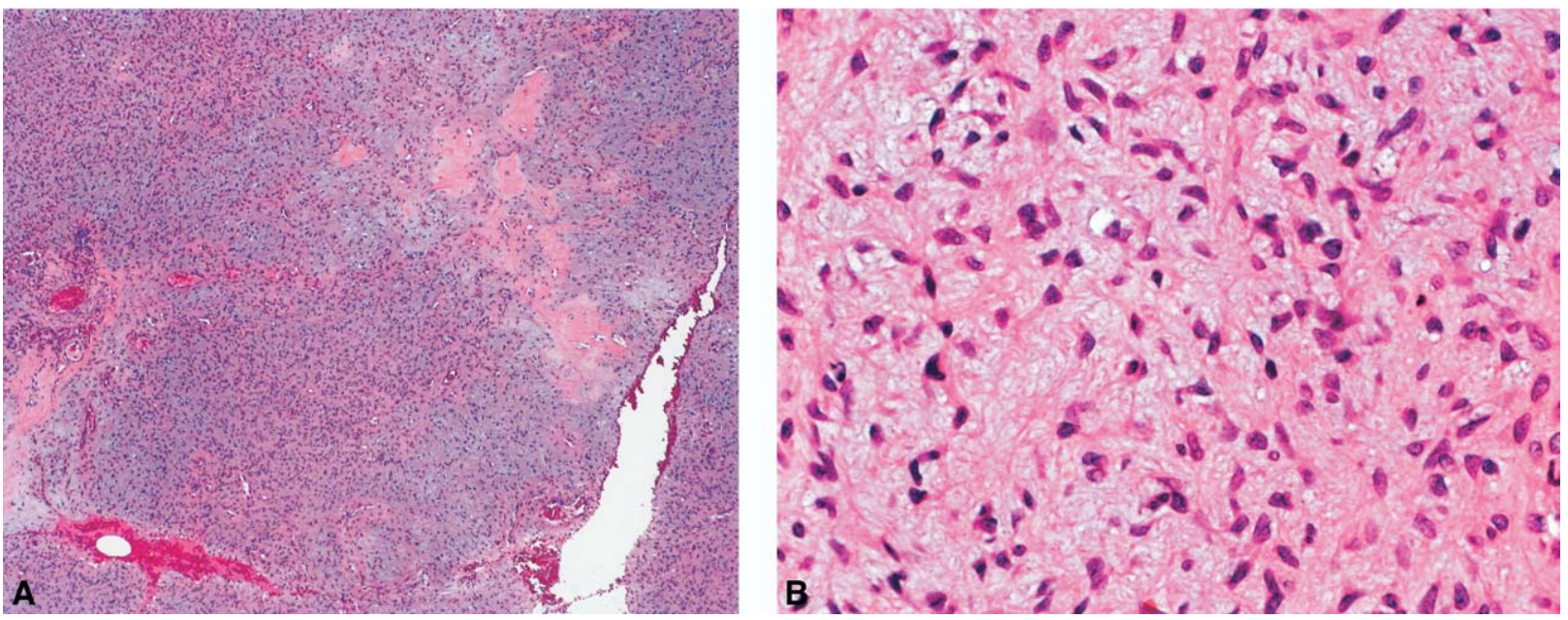

Figure 2. Histologic examination (hematoxylin and eosin stain). A, The slightly lobular architecture composed of myxoid matrix populated by stellate or elongate cells. The myxoid areas were interspersed in a background of more cellular regions containing dilated sinusoidal vessels and focal hemorrhage (original magnification $\times 100$ ). $B$, There were practically no mitotic figures and cellular atypia was minimal (magnification, $\times 200$ ).

of the sternum in Japan. Since we found only 5 reports in other countries ${ }^{4}$ this is the sixth case reported worldwide in the English literature. Although en bloc removal was performed in some of the previous cases to decrease the local recurrence rate, ${ }^{4}$ good results of curettage and bone allograft implantation were reported by Lersundi and associates ${ }^{5}$ in other lesions. Therefore, we performed complete curettage of the lesion using an air drill and filled the space with bone allograft fragments after curettage. There has been no local recurrence to date, 3 years 6 months postoperatively. This surgical method seems to be a good option in the treatment of CMF, even in the sternum, to preserve the thoracic bone structure.

\section{References}

1. Jaffe HL, Lichtenstein L. Chondromyxoid fibroma of bone: a distinctive benign tumor likely mistaken especially for chondrosarcoma. Arch Pathol. 1948;45:541-51.

2. Campanacci M. Chondromyxoid fibroma: In: Campanacci M, editor. Bone and soft tissue sarcomas. New York: Springer-Verlag; 1999, p. 265-78.

3. JOA Musculoskeletal Tumor Committee. Bone Tumor Registry in Japan. Tokyo: National Cancer Center; 2002.

4. Song DE, Khang SK, Cho KJ, Kim DK. Chondromyxoid fibroma of the sternum. Ann Thorac Surg. 2003;75:1948-50.

5. Lersundi A, Mankin HJ, Mourikis A, Hornicek FJ. Chondromyxoid fibroma: a rarely encountered and puzzling tumor: Clin Orthop Relat Res. 2005;439:171-5. 